\title{
LA NEGOCIACIÓN INCOMPATIBLE COMO DELITO DE CORRUPCIÓN: ESTRUCTURA TIIPICA Y CRITERIOS DE IMPUTACIÓN
}

\author{
"Incompatible negotiation" as corruption offense: \\ wrongdoing structure and responsibility criteria
}

Dr. Juan Pablo Mañalich R.

\begin{abstract}
Resumen: Elartículo propone una reconstrucción del injusto del delito de negociación incompatible bajo el derecho penal chileno, entendido como un delito de peligro abstracto contra la probidad en el ejercicio de la función pública, constitutivo de una especie diferenciada de corrupción punible. Sobre la base de una concepción fundada en la así llamada "metáfora contractual", se examina la estructura típica del delito, tanto en lo concerniente a su estatus como delito especial propio como en lo atingente a la determinación precisa de su núcleo típico, que se identifica con la intervención "interesada" de un funcionario público en un determinado contrato, negocio u operación. Finalmente, el trabajo analiza algunos pormenores de los presupuestos de imputación de la realización del tipo en lo específicamente tocante a la constitución del dolo y de la consciencia de la antijuridicidad.
\end{abstract}

Palabras clave: corrupción- delitos contra la función pública- negociación incompatible-cohecho-imputación subjetiva.

Abstract: The paper defends a reconstruction of the wrongfulness of the so called "incompatible negotiation" under Chilean criminal law, which can be understood as an "abstract endangerment" offense against probity in the exercise of public service and thus constitutes a differentiated kind of criminal corruption. Upon a conception based on the so called "contractual metaphor", the structure of the wrongdoing of the offense is analyzed, aiming towards its status as "special offense" as well as towards the precise definition of its wrongfulness core, which can be identified with the "interested" intervention of a public servant in a certain transaction or operation. In connection hereto, the specific conditions of subjective responsibility are reviewed, with regard both to mens rea and the awareness of unlawfulness.

Key words: corruption-offenses against public service -incompatible negotiation -bribery-subjective responsibility

*Profesor asociado del Departamento de Ciencias Penales, Universidad de Chile; correo electrónico:jpmanalich@,derecho.uchile.cl.

Este artículo fue recibido el 27 de mayo de 2015, siendo aprobada su publicación el 30 de diciembre de 2015. 
Mañalich - La negociación incompatible como delito de corrupción...

\section{La negociación incompatible como delito de peligro abstracto contra la probidad en el ejercicio de la función pública}

\subsection{Corrupción delictiva: la metáfora contractual}

En un sentido que todavía habrá que clarificar, el delito de negociación incompatible es un delito de corrupción. Esto nada dice, por de pronto, acerca del bien jurídico específicamente menoscabado por un hecho constitutivo de negociación incompatible. Pues el concepto de corrupción no designa la afectación de un bien jurídico determinado, sino más bien un determinado modo de ataque a uno o más bienes jurídicos. ${ }^{1}$ En estos términos, por "corrupción" cabe entender, siguiendo a Kindhäuser, una "vinculación contraria a intereses de una ventaja con el ejercicio de un poder de decisión transferido". Esto quiere decir que la existencia de una situación de corrupción presupone, en primer lugar, que una persona esté habilitada para ejercer algún poder de decisión en interés de otro(s); en segundo lugar, que el ejercicio de ese poder decisión quede vinculado a la obtención de una ventaja indebida; y en tercer lugar, que el carácter indebido de esa ventaja se funde en la incompatibilidad entre la obtención de esa ventaja y la promoción del interés al que ha de servir el ejercicio del poder de decisión en cuestión. ${ }^{3}$

Aquí interesa un ámbito particular en el cual la posibilidad de corrupción, en cuanto "modo de ataque", se presenta como especialmente amenazante, a saber: el ámbito en el cual el ejercicio del respectivo poder de decisión se corresponde con el desempeño de una función pública. Pues ello se traduce en que el ejercicio de ese poder de decisión quede legitimado por su contribución a la realización de una determinada finalidad pública, de manera tal que la vinculación de una ventaja inconexa al ejercicio de ese mismo de decisión tenga la potencialidad de comprometer la realización de esa misma finalidad. En tal medida, la corrupción en el desempeño de una función pública afecta el núcleo del principio de probidad administrativa, consistente en la exigencia de que la respectiva función sea ejercida dando "preeminencia del interés general sobre el interés particular", tal como lo establece el inc. $2^{\circ}$ del art. 52 de Ley 18.575, Orgánica Constitucional de Bases Generales de Administración del Estado.

De las concreciones del principio de probidad que se encuentran especificadas en el art. 53 de la misma Ley 18.575, la corrupción en el ejercicio de la función pública resulta distintivamente incompatible con la observancia de la exigencia de imparcialidad. Desde este punto de vista, por lo demás, puede tematizarse la particularidad exhibida por la específica forma de corrupción implicada en un delito de negociación incompatible, si se la compara con el paradigma de corrupción delictiva, constituido por el cohecho. Pues lo distintivo

\footnotetext{
${ }^{1}$ KINDHÄUSER (2007), p. 2.

${ }^{2}$ KindHÄUSER(2007), p. 6.

${ }^{3}$ En detalle KINDHÄUSER (2007), pp. 4 ss.
} 
del cohecho es que la ventaja indebidamente asociada al ejercicio de la función pública es ofrecida por, o solicitada de, alguna otra persona. ${ }^{4}$ Esto último se deja esclarecer en términos de lo que cabría denominar la "metáfora contractual", tomada como clave de reconstrucción dogmática de la estructura típica del cohecho. Ello hace posible clarificar la estructura típica del cohecho a través de un recurso a la noción de un "contrato" - el cual obviamente adolecería de "objeto ilícito"- a cuya "celebración" se orienta el comportamiento de las dos "partes" que vienen en consideración, a saber: la persona del funcionario público eventualmente sobornado, como posible "vendedor", y la persona del eventual sobornador, como posible "comprador". Y la "venta" en cuestión, en caso de llegar a "perfeccionarse", habría de encontrarse referida a una "prestación" consistente en la ejecución o la omisión de un acto institucionalmente conectado con el ejercicio de la función pública desempeñada por el primero, frente a lo cual el beneficio a ser recibido (por el funcionario) de parte del eventual sobornador representa el correspondiente "precio".

Semejante reconstrucción de la estructura típica del cohecho tiene su contexto más natural en la tradicional caracterización del cohecho como un delito de encuentro ("bilateral"). ${ }^{6}$ Sin embargo, la regulación legal actualmente vigente en Chile vuelve implausible esta última caracterización, precisamente por la configuración autónoma del injusto típico del cohecho "pasivo", por un lado, y del soborno (o "cohecho activo"). Esto concierne directamente a la determinación de sus respectivas condiciones de consumación, que todavía se encuentran recíprocamente configuradas bajo los arts. 248 y siguientes del Código Penal: la "solicitud de recibir" por parte del funcionario se corresponde con el "consentimiento en dar" por parte del potencial sobornador, mientras la "aceptación de recibir" por parte del funcionario se corresponde con el "ofrecimiento en dar" por parte del potencial sobornador. Notablemente, en tal correlación de las dos variantes que pueden asumir, respectivamente, el cohecho ("pasivo") y el soborno, todavía parece exhibir alguna vigencia(parcial) la apelación a la estructura de un delito de encuentro. Para comprobar esto basta con considerar la pregunta acerca de los presupuestos de la variante de cohecho consistente en la "aceptación de recibir" por parte del funcionario: conceptualmente, el funcionario no puede aceptar recibir (algo) a menos que otra persona le haya ofrecido dar (algo). Y lo mismo sucede, mutatis mutandis, tratándose de la variante de soborno consistente en el "consentimiento en dar" por parte del particular: conceptualmente, una persona no puede consentir en dar (algo) a menos que otra -aquí: el funcionario-haya solicitado recibir (algo).

\footnotetext{
${ }^{4}$ KINDHÄUSER (2007), pp. 7 s. En general sobre la estructura típica del cohecho bajo el derecho penal chileno, véase OLIVER (2004), pp. 88 ss., 96 ss.

${ }_{5}^{5}$ Para semejante aproximación, véase ya CARRARA (1961), pp. 94 ss., 101 s.; también BINDING (1905), pp. 712 ss.

${ }^{6}$ Véase solo LABATUT (2005), tomo II, p. 90. Que semejante caracterización no supone, empero, asumir que sobornado y sobornador serían co-intervinientes en un mismo delito, fue muy claramente advertido ya por BELING (1906), pp. 272 ss.
} 
Mañalich - La negociación incompatible como delito de corrupción...

Obviamente, lo anterior no es casualidad. En uno y otro caso, se trata de variantes típicas definidas por la circunstancia de que el respectivo autor aparece, en términos de la metáfora contractual, ocupando la posición de aceptante frente a una oferta ajena. Y por definición, la posibilidad de aceptación de una oferta presupone la existencia de una oferta. Pero esto basta para advertir, a contrario sensu, por qué resultan problemáticas, desde el punto de vista de la tesis del delito de encuentro, las otras dos constelaciones, esto es, la de cohecho ("pasivo") en la cual el funcionario solicita (recibir) y la desoborno en la cual la otra persona ofrece (dar). Pues aquí el autor de la respectiva variante típica aparece ocupando, también en términos de la metáfora contractual, la posición de oferente. Y la posición de oferente, si bien presupone la existencia de un destinatario de la oferta, no depende de que este último efectivamente se convierta en aceptante.

Luego, la tesis del delito de encuentro carece de rendimiento reconstructivo para dar cuenta del conjunto de las variantes de cohecho y soborno tipificadas en los arts. 248 y siguientes del Código Penal chileno. Pero esto no quiere decir que, entonces, semejante concepción pierda toda su significación heurística. ${ }^{7}$ Pues para entender en qué consiste, en cada caso, la respectiva forma de comportamiento con relevancia típica, sigue siendo imprescindible tener en cuenta el carácter interdependiente de las posiciones del funcionario y del eventual sobornador: lo que uno u otro hace ha de ser juzgado en atención al significado de su comportamiento en referencia al acuerdo de voluntades que el respectivo agente pretende alcanzar con la otra persona, a pesar de que dicho acuerdo de voluntades no necesite llegar a producirse para los efectos de la consumación del hecho -individual- eventualmente imputable a uno u otro, según corresponda.

\subsection{La negociación incompatible como "auto-contratación” delictiva}

Si en el cohecho la ventaja indebida es ofrecida por, o solicitada de, una persona distinta del funcionario de cuya "corrupción" se trata, en la negociación incompatiblela ventaja en cuestión está asociada, como observara Soler, a "un desdoblamiento de la personalidad del funcionario, de manera que a un tiempo resulte intervenir en una relación (contrato u operación) como interesado y como

\footnotetext{
7 Con ello también se obtiene una clave para la demarcación de los ámbitos típicos del cohecho ("pasivo") y de la exacción ilegal o "concusión". Desde luego, su potencial superposición solo afecta aquellas formas de cohecho que satisfacen las siguientes dos condiciones: (1) que se trate de un posible cohecho "simple" (del art. 248), dado que el art. 241 solo comprende la situación del funcionario que exige recibir un beneficio para ejecutar o por haber ejecutado "un acto propio de su cargo"; y (2) que el funcionario "solicite", esto es, que se comporte como oferente, puesto que solo aquí cabría plantear la cuestión de si lo que hace el funcionario pudiera también satisfacer la descripción de "exigir" (art. 241). Pero lo decisivo es que, bajo la tipificación de la concusión, la "prestación" indebidamente exigida por el funcionario público no pretende exhibir, tampoco frente al destinatario de esa misma exigencia, "legitimidad contractual" sobre la base de un acuerdo de voluntades intersubjetivamente vinculante.
} 
órgano del Estado". ${ }^{8}$ Esto quiere decir, para proseguir con la metáfora contractual, que la forma de corrupción distintiva de la negociación incompatible, al menos en atención a su variante más paradigmática, se deja reconstruir en el sentido de una "auto-contratación" delictiva."

En términos que serán clarificados más adelante, esto último se traduce en que es el interés que el funcionario público toma en un contrato o una operación en la cual le corresponde intervenir por razón de su cargo lo que confiere significación delictiva a esa misma intervención. Pues en tal medida, su intervención en el contrato o la operación en cuestión se deja interpretar como una prestación que el funcionario efectúa en promoción de su propio interés. Y siendo esta la variante más paradigmática de negociación incompatible, la apelación metafórica a la noción de un injusto de "auto-contratación" no deja de tener pertinencia para la determinación del alcance de sus variantes menos paradigmáticas, bajo las cuales el interés con potencialidad corruptiva se atribuye no al propio funcionario sino a una persona familiarmente vinculada con aquél, o bien a una persona o entidad profesional o comercialmente relacionada con esta.

Sobre esta base, cabe ofrecer una caracterización preliminar del delito de negociación incompatible, cuyo rendimiento habrá de ser sometido a comprobación en lo que sigue. La negociación incompatible, tal como se encuentra tipificada en el art. 240 del Código Penal, se deja entender como un delito cuyo injusto específico consiste en un menoscabo del correcto ejercicio de la función pública. Y ese menoscabo, al igual como sucede en referencia al cohecho, admite ser caracterizado en la forma de un peligro abstracto, ${ }^{10}$ constituido por la vulneración de condiciones de las cuales depende que la función pública no sea ejercida de un modo que subvierta la preeminencia del interés general sobre el interés particular. Así se deja entender, por lo demás, la observación de Soler en cuanto a que la prohibición de la negociación incompatible serviría a la protección "del fiel y debido desempeño de las funciones de la administración en sentido amplio", en el sentido deque lo que aquí está en juego es asegurar "que la actuación de los órganos no solo sea imparcial, sino que se encuentre a cubierto de toda sospecha de parcialidad". 11

\footnotetext{
8 SOLER (1992), tomo V, p. 246.

9 Acerca de la estructura del auto-contrato como paradigma de una situación de "conflicto de intereses" potencialmente resultante en la infracción de deberes fiduciarios concernientes al ejercicio de potestades conferidas para la gestión y promoción de intereses ajenos, véase PARDOW (2008), pp. 570 ss., con referencias ulteriores.

10 Así Politoff, Matus y RAMíREZ (2004), p. 477. En relación con el cohecho y las figuras directamente emparentadas con este, KINDHÄUSER (2007), pp. 9 ss.

11 SOLER (1992), p. 246, añadiendo que la estructura del delito sería la de un "delito formal en el sentido de que no requiere la producción de un daño".Precisamente esta consideración llevaba a CURY (1986), pp. 300 s., a proponer, enfáticamente, la descriminalización de tal forma de comportamiento.
} 
Mañalich - La negociación incompatible como delito de corrupción...

\section{La estructura típica de la negociación incompatible}

\subsection{La negociación incompatible como delito especial}

A partir de la caracterización precedente, corresponde entrar ahora en el análisis de la estructura típica de la negociación incompatible.Lo primero que cabe establecer es que se trata de un delito especial (propio). ${ }^{12}$ Esto se traduce, desde ya, en que como autor solo pueda venir en consideración un intraneus, esto es, una persona que ostente el estatus de "empleado público", en el sentido en que este concepto se encuentra definido en el art. 260 del Código Penal. ${ }^{13}$ En estos términos,solo puede ser autor del delito de negociación incompatible una persona "que desempeñe un cargo o función pública, sea en la administración central o en instituciones o empresas semifiscales, municipales, autónomas y organismos creados por el Estado o dependientes de él".

A este respecto, la única salvedad se encuentra referida a lo dispuesto en el inc. $2^{\circ}$ del art. 240, que extiende el círculo de autoría a "los peritos, árbitros y liquidadores comerciales, respecto de los bienes o cosas en cuya tasación, adjudicación, partición o administración intervinieren", así como a "los guardadores y albaceas tenedores de bienes respecto de los pertenecientes a sus pupilos y testamentarías".

\subsection{La intervención "interesada" del funcionario público como núcleo típico}

El delito tipificado en el art. 240 exhibe una estructura que combina dos variantes alternativas: la primera consiste en que el funcionario público se interese, directa o indirectamente, en algún contrato o alguna operación en la cual haya de intervenir por razón de su cargo (inc. $1^{\circ}$ ); la segunda, por su parte, en que el funcionario, "en el negocio u operación confiados a su cargo", dé interés a alguna persona o entidad relacionada con él. Esta segunda modalidad se deja descomponer en dos subvariantes, según cuál sea la relación que vincula al funcionario con la persona o entidad de cuyo interés se trata. En efecto, puede tratarse de una persona vinculada con él por matrimonio o por parentesco, ya sea por consanguinidad o afinidad en la línea recta o solo por consanguinidad en la línea colateral hasta el tercer grado inclusive (inc. $\left.3^{\circ}\right) ;{ }^{14}$ o puede tratarse de algún tercero asociado con el

\footnotetext{
12 Sobre los presupuestos y las implicaciones de semejante caracterización, véase MAÑALICH (2012), pp. 358 ss.

${ }^{13}$ Un extraneus -esto es, una persona en quien no se satisface la cualidad especial en cuestión- a lo sumo podría responder como partícipe, y no como autor, de la realización del tipo, tal como ello resulta determinado por el principio de la accesoriedad de la participación.

${ }^{14}$ Esta formulación se justifica por el hecho de que las categorías de "padres o hijos naturales o ilegítimos" resultan actualmente obsoletas, a consecuencia de la supresión de la diferenciación de los regímenes de filiación legítima e ilegítima, operada a través de la Ley 19585, de 26 de octubre de 1998.
} 
propio funcionario o con alguna de las personas indicadas en el inc. $3^{\circ}$, o bien de una sociedad, asociación o empresa en la cual alguna de las personas indicadas en el inc. $3^{\circ} \mathrm{o}$ algún tercero asociado con ellas tenga un interés social superior al 10\%, tratándose de una sociedad anónima, o ejerza la administración en cualquier forma (inc. $4^{\circ}$ ).

Por el momento, cabe determinar cuál es el alcance las fórmulas utilizadas por la ley para especificar cada una de las dos modalidades básicas. Pues a primera vista al menos, el tenor literal del art. 240 sugiere que el núcleo típico consistiría, respectivamente, en que el funcionario o bien se interese o bien dé interés a alguna otra persona en la respectiva gestión, lo cual podría dar pie a la caracterización de la técnica legislativa empleada como un tanto "artificiosa". ${ }^{15} \mathrm{La}$ dificultad queda disipada, empero, cuando - en la línea de lo sostenido por un sector sumamente representativo de la doctrina- se advierte que es en la intervención del funcionario público en el correspondiente contrato, negocio u operación donde radica el núcleo típico, ${ }^{16}$ conclusión que encuentra apoyo decisivo en la propuesta de reconstrucción del contenido de injusto de la negociación incompatible a partir de la metáfora contractual. Pues el sentido en el cual cabe caracterizar -metafóricamente- la negociación incompatible como un delito de "autocontratación" se corresponde con el hecho de que es en la intervención del funcionario en la correspondiente operación -sea que esta exhiba o no naturaleza contractual- donde ha de encontrarse la materialización de la vulneración del principio de probidad como estándar de comportamiento para el desempeño de la función pública.

Lo anterior significa, más precisamente, que el comportamiento punible a título de negociación incompatible no consiste sino en que el funcionario intervenga en el asunto o gestión en interés propio, bajo la primera modalidad, o bien en interés de alguna persona o entidad relacionada con él, bajo la segunda modalidad. Y tratándose de la primera modalidad, tal como lo prevé el inc. $1^{\circ}$, la intervención auto-interesada del funcionario puede tener lugar tanto directa como indirectamente, esto es: o bien sin mediación de persona alguna, o bien a través de una persona interpuesta, como lo sería, característicamente, un testaferro o "palo blanco". ${ }^{17}$

En cuanto a la naturaleza del interés particular -propio o ajeno- a cuyo favorecimiento ha de orientarse la intervención del funcionario, en la doctrina prevalece hegemónicamente la tesis de que el interés en cuestióntiene que ser de

\footnotetext{
15 Así se pronunció la mismísima Corte Suprema, por sentencia del 23 de marzo de 1999, rol No 2133-98, redactada por el ministro Enrique Cury; véase su considerando 16.

16 Véase LABATUT (2005), p. 84; ETCHEBERry (1998), tomo IV, p. 248; Rodríguez y OSSANDÓN (2008), p. 425.

${ }^{17}$ ETCHEBERRY (1998), p. 249; RODRÍGUEZ y OSSANDÓN (2008),p. 424.
} 
Mañalich - La negociación incompatible como delito de corrupción...

índole económica. ${ }^{18}$ Pero se encuentra asimismo fuera de discusión, en todo caso, que la efectiva obtención del beneficio o la ventaja asociada a la intervención del funcionario carece de toda relevancia típica. Esto quiere decir que para que el delito de negociación incompatible se encuentre consumado, no es necesario en lo absoluto que el beneficio o la ventaja en efecto lleguen materializarse para el propio funcionario, bajo la primera modalidad típica, o bien para la persona o entidad con él relacionada, bajo la segunda. ${ }^{19}$ Antes bien, para la consumación del delito basta con que el funcionario tome parte en el asunto o gestión "interesadamente", en el sentido ya indicado. ${ }^{20} \mathrm{La}$ irrelevancia de que el funcionario interviniente o la persona o entidad con él relacionada, según corresponda, llegue o no a obtener la ventaja o el beneficio proyectado se ve, por lo demás, manifiestamente confirmada por el generalizado aserto según el cual la realización del tipo de la negociación incompatible no se ve mínimamente trastocada por la eventualidad de que el funcionario -o la persona o entidad con él relacionada- termine sufriendo, en contra de lo esperado, un perjuicio económico a consecuencia de su intervención interesada en el negocio o la operación de que se trate. ${ }^{21}$

Lo anterior no se ve desafiado por la manera en que, de acuerdo con la parte final del inc. $1^{\circ}$, se determina la cuantía de la pena de multa a ser impuesta -además de la correspondiente pena privativa de libertad- sobre el funcionario que incurriere en negociación incompatible, la cual ha de consistir en un valor que puede ir del 10 al 50\% del interés que el funcionario "hubiere tomado en el negocio". Si bien esto ciertamente avala la interpretación que cualifica el interés en cuestión como uno de naturaleza económica, ${ }^{22}$ lo que interesa aquí es la constatación de que para la determinación de la magnitud de la multa es totalmente irrelevante que "el interés se concrete, se materialice", sino que "es suficiente tenerlo". ${ }^{23}$

Que la negociación incompatible exhiba el carácter de un delito de peligro abstracto, según lo ya sostenido, resulta de la máxima significación para dar cuenta de que la realización del tipo del art. 240 no se ve puesta en cuestión si, eventualmente, la intervención interesada del funcionario pudiera incluso redundar en un beneficio económico para el propio Estado. En la certera formulación de Soler: "El hecho no pierde su carácter por la circunstancia de que de él haya

\footnotetext{
18 Véase RodríGUEZ (1991), p. 1193; SOLER (1992), p. 247. De otra opinión SANCINETTI (1986), pp. 882. En la doctrina chilena, véase ETCHEBERRY (1998), pp. 248 s.; GARRIDO (2010), p. 458; POLITOFF, MATUS y RAMíREZ (2004), p. 477; RODRÍGUEZ y OSSANDÓN (2008), p. 424.

${ }^{19}$ ETCHEBERry (1998), p. 249; RODRÍGUEZ y OSSANDÓN (2008), p. 423.

20 Así Soler (1992), p. 248. ETCHEBERry (1998), p. 249, va demasiado lejos cuando sostiene que no sería necesario, "incluso, que el empleado llegue efectivamente a intervenir"; en igual sentido RODRÍGUEZ y OSSANDÓN (2008), p. 424.

${ }^{21}$ Así ya Cuello (1957), p. 417; en el mismo sentido ETCHEBERRY (1998), p. 249.

22 Así ETCHEBERRY (1998), pp. 248 ss.; GARRIDO (2010), p. 458; RODRÍGUEZ y OSSANDÓN (2008), p. 424.

${ }^{23}$ GARRIDO (2010), p. 458.
} 
derivado una concreta ventaja económica, porque la prohibición se funda en la idea de prevención genérica de los daños que con mucha más frecuencia derivarían si se adoptara el criterio opuesto". ${ }^{24}$

\subsection{La naturaleza del contrato, negocio u operación objeto de la intervención interesada del funcionario público}

Para especificar en qué ha de consistir la gestión o el asunto al cual ha de encontrarse referida la intervención interesada del funcionario, el art. 240 recurre indistintamente a las expresiones "contrato u operación" (inc. $1^{\circ}$ ) y "negocio u operación" (inc. $3^{\circ}$ y $4^{\circ}$ ). Esto muestra, desde ya, que resultaría inadmisible una interpretación que restringiera el alcance del tipo de la negociación incompatible a la intervención del respectivo funcionario en la preparación o celebración de uno o más contratos. Antes bien, y como observa Garrido, las expresiones a las que aquí recurre la ley han de ser entendidas "en un sentido amplio", en el sentido de que ellas hacen referencia "a cualquier acuerdo de voluntades o a cualquier trabajo o negocio donde el empleado tenga intervención en su calidad de funcionario, sin distinción de su naturaleza". ${ }^{25}$ A esto último hay añadir que la gestión u operación en cuestión ha de tener significación económica, ${ }^{26}$ pues de ello depende que en la intervención del funcionario en ella pueda quedar asociada a la persecución de un interés pecuniariamente cuantificable. $\mathrm{Y}$ ciertamente: el negocio, contrato $\mathrm{u}$ operación ha de encontrarse comprendido en el ámbito de competencia del funcionario, que es precisamente lo que determina que la intervención de este tenga lugar "por razón de su cargo".

Aquí es decisivo, en todo caso, no perder de vista que el potencial autor no necesita en modo alguno estar investido de "la plena potestad para decidir individualmente el negocio como funcionario", siendo a todas luces bastante, antes bien, "que concurra a formar la determinación sustancial o a fijar la legalidad de la operación". ${ }^{27}$ Pues para que se vea configurada la específica ilicitud que distingue a la negociación incompatible es suficiente que el funcionario intervenga meramente "condicionando la voluntad negocial de la Administración, por la inserción del interés particular". ${ }^{28}$

\footnotetext{
${ }^{24}$ SOLER (1992), p. 246; en el mismo sentido ETCHEBERRY (1998), p. 249.

${ }^{25}$ GARRIDO (2010), p. 458.

26 Así RodrígueZ y OSSANDÓN (2008), p. 425.

${ }^{27}$ SOLER (1992), p. 247.

${ }^{28}$ SANCINETTI (1986), p. 881.
} 
Mañalich - La negociación incompatible como delito de corrupción...

\section{Problemas de imputación subjetiva: dolo y conciencia de la antijuridicidad}

\subsection{La suficiencia del dolo eventual}

Habiendo sido ya delimitado el alcance de la tipificación del delito del art. 240 del Código Penal, puede ser conveniente ahora examinar someramente algunas cuestiones concernientes a la manera en que los criterios generales de imputación subjetiva se hacen operativos en referencia a la realización del tipo de la negociación incompatible. En lo fundamental, estas cuestiones se refieren a la forma y el contenido del dolo, por una parte, y a la exigencia de consciencia de la antijuridicidad, por otra. ${ }^{29}$

Si bien algunas voces de la doctrina chilena se inclinan por proponer una restricción del título de imputación subjetiva para la punibilidad de la negociación incompatible al dolo directo, ${ }^{30}$ no hay razón alguna para descartar la suficiencia del dolo eventual a este respecto. Pues el dolo eventual constituye, por de pronto, la forma básica de dolo, ${ }^{31}$ en circunstancias de que el texto del art. 240 no contiene cláusula alguna -como podría serlo la expresión "a sabiendas"- que pudiera fundamentar la exigencia de una forma cualificada de dolo.

Antes bien, y como acertadamente observa Soler, para la imputación de una negociación incompatible a título de dolo basta con "el conocimiento de la condición del negocio en que se interviene como doblemente sometido a la consideración del sujeto", ${ }^{32}$ en circunstancias de que el umbral mínimo para ese mismo conocimiento ha de quedar asociado, con arreglo a los criterios generales, a la categoría del dolo eventual. Esto quiere decir, en particular, que para que la realización del tipo sea imputable al funcionario a título de dolo es en todo caso suficiente que este se haya representado, con un grado de probabilidad decisoriamenterelevante, que su intervención en el respectivo negocio u operación involucraba la promoción de un interés económico para sí o para alguna persona o entidad relacionada con él según lo previsto en los inc. $3^{\circ}$ y $4^{\circ}$ del art. 240 . De esto se sigue que, como sostiene Soler, "[n]o se requiere un propósito especial de defraudar o perjudicar ni tampoco el de un lucro ilícito, aun cuando -observa con ironía- prácticamente estos hechos no suelen ejecutarse con fines de beneficencia". ${ }^{33}$

\footnotetext{
${ }^{29}$ Aquí no interesa entrar en la pregunta de cómo se relacionan, sistemáticamente, las categorías del dolo y la consciencia de la antijuridicidad; en detalle al respecto, MAÑALICH (2011), pp. 98 ss., 102 ss., 108 ss.

${ }^{30}$ GARRIDO (2010), p. 458; RODRÍGUEZ y OSSANDÓN (2008), p. 426.

31 Véase solo HERNÁNDEZ (2011), pp. 73 s.

32 SOLER (1992), p. 248.

${ }_{33}$ Ibid, pp. 248 ss.
} 


\subsection{Consciencia de la antijuridicidad y error de prohibición}

En lo concerniente a la exigencia -asimismo general- de conocimiento de la antijuridicidad, es interesante tener en cuenta que, precisamente en referencia al delito tipificado en el art. 240, la Corte Suprema reconoció por primera vez, en un pronunciamiento del año 1999, la eficacia eximente de un error de prohibición directo, en la medida en que se trate de un error invencible. ${ }^{34}$ Aquí puede ser útil dar cuenta de los criterios que para ello ofreció la Corte. ${ }^{35}$

La Corte comenzó apuntando que las situaciones en que en principio sería viable reconocer un error de prohibición directo e invencible serían fundamentalmente de dos especies, a saber: situaciones de "choques de culturas con percepciones valorativas muy contrastantes", por un lado; y situaciones que involucran a "personas con escasa o ninguna formación jurídica, pertenecientes a comunidades más o menos apartadas y sencillas, y sin asistencia legal, frente a tipos [delictivos] sofisticados que describen comportamientos probablemente lesivos de la convivencia, pero que no repugnan 'prima facie' a los sentimientos de justicia de individuos como los descritos", 36 por otro (c. 13).

Sobre tal base, la Corte otorgó importancia a la circunstancia de que, tratándose de un hecho delictivo presuntamente perpetrado por un alcalde en el ejercicio de sus funciones, la municipalidad no hubiera contado con un asesor jurídico $\left(\right.$ c. $\left.15^{\circ}\right)$. Ello sería de especial relevancia en atención a que el tipo delictivo del art. 240 del Código Penal tendría "características extremadamente artificiosas [...], cuyas peculiaridades, límites y significado [...] escapan a veces a la inteligencia de juristas avezados, y cuya existencia es ignorada incluso hasta por muchos letrados" (c. $16^{\circ}$ ). Si bien la Corte complementó lo anterior invocando lo exiguo de "la jurisprudencia que se puede encontrar al respecto, la cual ha afectado usualmente solo a individuos ilustrados" (c. $16^{\circ}$ ), hay que tener en consideración que, con posterioridad a su fallo, se registran importantes pronunciamientos emitidos por tribunales superiores de justicia a este respecto. ${ }^{37}$

Asimismo, la Corte hizo mención del grado de formación educacional del imputado $\left(\right.$ c. $\left.16^{\circ}\right)$, así como del comportamiento que este habría exhibido a lo largo del proceso penal correspondiente, el cual habría hecho reconocible una "sencillez casi candorosa con que reconoce su participación en los hechos, los

\footnotetext{
34 Véase supra, nota $\mathrm{n}^{\circ} 15$.

${ }^{35}$ En detalle acerca de lo que sigue, véase MAÑALICH (2012), pp. 34 ss.

${ }^{36}$ No está de más reparar en que el fallo fue redactado por el ministro Enrique Cury, quien en su faceta de jurista académico había ya abogado por la supresión de la tipificación de la negociación incompatible; véase supra, nota $\mathrm{n}^{\circ} 11$.

${ }^{37}$ Véase por ejemplo la sentencia de la Corte Suprema, de fecha $1^{\circ}$ de septiembre de 2008 , rol $\mathrm{N}^{\circ}$ 5903-2007; así como las sentencias de la Corte de Apelaciones de Santiago, de fecha 28 de octubre de 2005, rol No 23015-2001, y de la Corte de Apelaciones de Valparaíso, de fecha 26 de marzo de 2010, rol No 207-2010.
} 
Mañalich - La negociación incompatible como delito de corrupción...

cuales relata como algo que carece de toda reprobabilidad" (c. $17^{\circ}$ ), para finalmente destacar que en la localidad en que tuvieron lugar los acontecimientos "la realización de transacciones entre el alcalde y un negocio de su propiedad o la de parientes se miraba en Salamanca como algo normal y generalmente aceptado, que no generaba censura ni sospecha de ilicitud"' (c. $18^{\circ}$ ). De este modo, la Corte concluía que "en el medio cultural en el que le correspondió desempeñarse al encausado la ilicitud de las negociaciones incompatibles era completamente desconocida y que los integrantes del conglomerado social las apreciaban como no reprobables, sin que este contara siquiera con indicios que pudieran alertarlo sobre la ilegitimidad de su comportamiento" (c. 19).

Los criterios ofrecidos por la Corte en los considerandos así reseñados son de importancia, entonces, para establecer cuáles tendrían que ser los estándares para juzgar si el eventual desconocimiento de la ilicitud de un comportamiento constitutivo de negociación incompatible pudiera fundamentar una eximente de responsabilidad por error de prohibición invencible. Es crucial tener en cuenta, empero, que aquí se trata criterios para fundamentar el carácter eventualmente invencible de un posible error de prohibición, alegación que tendría que ser sustentada en pos de desvirtuar la presunción -simplemente legal- de conocimiento de la antijuridicidad, la cual, de acuerdo con la mejor interpretación disponible, se encuentra contenida en el inc. $2^{\circ}$ del art. $1^{\circ}$ del Código Penal, en la forma de una "presunción de voluntariedad". ${ }^{38}$ Esto quiere decir, a contrario sensu, que no habiendo antecedente alguno que sugiera que el potencial autor pudo desconocer la ilicitud de su comportamiento, habrá que asumir que aquel efectivamente tenía consciencia de la contrariedad a derecho de su actuar.

\footnotetext{
${ }^{38}$ En detalle al respecto MAÑALICH (2011), pp. 111 ss.
} 


\section{BIBLIOGRAFÍA}

* BELING, Ernst (1906): Die Lehre vom Verbrechen, J.C.B. Mohr (Paul Siebeck), Tubinga.

* BINDING, Karl (1905): Lebrbuch des Gemeinen Deutschen Strafrechts, tomo II, Wilhelm Engelmann, Léipzig.

* CARrara, Francesco (1961): Programa de Derecho Criminal. Parte Especial, vol. V, Temis, Bogotá.

* CUEllo Calón, Eugenio (1957): Derecho Penal, tomo II, 10ª ed., Bosch, Barcelona.

* CURY, Enrique (1986): "Contribución político-criminal al estudio de los delitos funcionarios (descriminalización y administrativización)",Revista Chilena de Derecho vol. 13, $\mathrm{N}^{\mathrm{o}}$ 2, pp. 295-304.

* ETCHeberry, Alfredo (1998): Derecho Penal Parte Especial, tomo IV, $3^{\text {a }}$ ed., Editorial Jurídica de Chile, Santiago.

* GARRIDO, Mario (2010): Derecho Penal Parte Especial, tomo III, $4^{a}$ ed., Editorial Jurídica de Chile, Santiago.

* HERNÁNDEZ, Héctor (2011): “Art. 1””, en: COUSO, Jaime, y HERNÁNDEZ, Héctor (dirs.), Código Penal Comentado. Libro Primero, AbeledoPerrot-Legal Publishing, Santiago, pp.7-105.

* KINDHÄUSER, Urs (2007): "Presupuestos de la corrupción punible en el Estado, la economía y la sociedad. Los delitos de corrupción en el Código penal alemán", Política Criminal vol. 2, No 3, en: http://politicacriminal.cl/n 03/a 1 3.pdf.

* Labatut, Gustavo (2005): Derecho Penal, tomo II, $7^{\mathrm{a}}$ ed., Editorial Jurídica de Chile, Santiago.

* MAÑAliCH, Juan Pablo (2011): "El delito como injusto culpable", Revista de Derecho $U A C h$ vol. 24, No 1 , pp. 87-115.

(2012): "Error de tipo y error de prohibición en los delitos contra la autodeterminación sexual”, Informes en Derecho. Doctrina Procesal Penal 2011, Defensoría Penal Pública, Santiago, pp. 23-77.

* _ (2012): "La malversación de caudales públicos y el fraude al fisco como delitos especiales", Politica Criminatvol. $7, \quad \mathrm{~N}^{\circ}$ 14, en: http://politicacriminal.cl/Vol 07/n 14/Vol7N14A4.pdf.

* OLIVER, Guillermo (2004): "Aproximación al delito de cohecho", Revista de Estudios de la Justicia 5, pp. 83-115.

* PARDOW, Diego (2008): "La parábola del administrador infiel: un estudio sobre los conflictos de intereses y el deber de lealtad”, en GUZMÁN BRITO, Alejandro (dir.), Estudios de Derecho Civil III, Santiago, Legal Publishing, pp. 567-582.

* POliTOFF, Sergio /MATUS, Jean Pierre /RAMÍREZ, María Cecilia (2004): Lecciones de Derecho Penal Chileno. Parte Especial, Editorial Jurídica de Chile, Santiago.

* RODRÍGUEZ, Luis, y OSSANDÓN, María Magdalena (2008): Delitos Contra la Función Pública, $2^{a}$ ed., Editorial Jurídica de Chile, Santiago.

* Rodríguez DeveSA, José María (1991): Derecho Penal Español. Parte Especial, 14a ed., Dykinson, Madrid.

* SANCINETTI, Marcelo (1986): "Negociaciones incompatibles con el ejercicio de funciones públicas", Anuario de Derecho Penaly Ciencias Penales vol. XXXIX, pp. 877-889.

* SOLER, Sebastián (1992): Derecho Penal Argentino, $4^{\text {a }}$ ed., Tea,Buenos Aires, tomo V. 